\title{
NILAI-NILAI KEPEMIMPINAN DALAM PERSPEKTIF AJARAN HINDU
}

\author{
Oleh \\ Kadek Hemamalini \\ Sekolah Tinggi Agama Hindu Dharma Nusantara Jakarta \\ kadekhema@gmail.com
}

Diterima

direvisi.

diterbitkan

\begin{abstract}
Leaders are people who are tasked to guide and direct the people they lead, a leader has a very heavy duty in directing the community he leads. A good leader is a leader who is capable of carrying out all duties and obligations as a leader and is able to direct the community he leads. In Hinduism itself there are goals of Hindu leadership which aim to form a good, strong, clean, and authoritative state leadership and Hindu leadership functions which consist of functions as motivational factors, as creative factors, as integrative factors, as sublimative or transformative factors, and as an inspiring factor. The criteria for leadership in Hinduism is to have a basic principle that is a guide in leading.
\end{abstract}

Keywords: Kepemimpinan dalam ajaran Hindu, Niti sastra, Kautilya Artha Sastra.

\section{PENDAHULUAN}

Manusia sebagai makhluk sosial, tentunya memerlukan orang lain untuk mencapai tujuan hidupnya. Sehingga, manusia berpikir untuk bekerjasama membentuk suatu kelompok atau komunitas dengan orang lain yang memiliki tujuan yang sama dengannya. Namun, pada dasarnya perlu bahwa manusia juga diciptakan dengan karakter yang berbeda-beda. Demikian juga yang akan terjadi dalam suatu kelompok yang dibentuk manusia itu sendiri. Maka dari itu, diperlukan seseorang yang memiliki kemampuan untuk menyatukan berbagai karakter yang berbeda. Orang tersebut disebut dengan pemimpin. Pemimpin harus memiliki seni untuk memimpin orang lain. Seni tersebut sering disebut dengan istilah kepemimpinan. Banyak orang bisa menjadi seorang pemimpin, tetapi tidak banyak di antara mereka yang memiliki kepemimpinan yang baik. Selebihnya, pendidikan agama juga berperan besar dalam mengajarkan seseorang untuk memimpin orang lain yang tentunya harus sesuai dengan kaidah agama yang dipercaya. Dalam hal ini, agama Hindu juga mengajarkan bagaimana seorang manusia dapat 
menjadi pemimpin yang baik dengan menjunjung nilai dharma.

Seorang pemimpin formal atau informal, besar maupun kecil melaksanakan kepemimpinan yang berbeda-beda derajat, bobot daerah jangkauan maupun sasaran yang hendak diwujudkannya. Tetapi suatu yang pasti adalah; pemimpin dan kepemimpinan selalu dikaitkan dengan tujuan yang hendak dicapai. Sebab pemimpin tanpa tujuan tidak ada artinya. Selain terikat dengan tujuan yang hendak dicapai, maka kepemimpinan tak dapat dilepaskan dengan masyarakat yang dipimpin. Tanpa masyarakat seorang pemimpin tak mempunyai fungsi, kehadirannya tak mempunyai arti. Adalah menjadi tugas seorang pemimpin untuk mengetahui apa yang benar-benar yang menjadi keinginan dan harapan masyarakat yang dipimpinnya. Mereka harus mampu mengadakan pendekatan yang menyentuh akal dan juga menyentuh hati masyarakatnya. Sebab dengan pendekatan yang demikian seorang pemimpin akan mampu merebut simpati masyarakat yang dipimpinnya. Hal itu memberikan bobot kepada kepemimpinannya dan sekaligus mempermudah memberikan motivasi yang kuat dan meyakinkan masyarakat untuk berbuat. Kepemimpinan seorang pemimpin diharapkan mampu mengilhami masyarakatnya dan sekaligus memberikan daya gerak yang kuat untuk mencapai tujuan.

\section{PEMBAHASAN}

Secara umum, kepemimpinan diartikan sebagai kemampuan untuk mengkoordinir dan mengerahkan orangorang serta golongan-golongan untuk tujuan yang diinginkan. Menurut William H.Newman (1968), kepemimpinan adalah kegiatan untuk memengaruhi perilaku orang lain atau seni memengaruhi perilaku manusia baik perorangan maupun kelompok. Bahasan mengenai pemimpin dan kepemimpinan pada umumnya menjelaskan bagaimana serta syaratsyarat apa yang perlu dimiliki untuk menjadi seorang pemimpin yang baik. Menyimak pengertian tersebut, maka terkait dengan kepemimpinan ada beberapa hal yang perlu diperhatikan. Pertama, kepemimpinan selalu melibatkan orang lain sebagai pengikut. Kedua, dalam kepemimpinan terjadi pembagian kekuatan yang tidak seimbang antara pemimpin dan yang dipimpin. Ketiga, kepemimpinan merupakan kemampuan menggunakan bentuk-bentuk kekuatan untuk memengaruhi perilaku orang lain. Keempat, kepemimpinan adalah suatu nilai (values), suatu proses kejiwaan yang sulit diukur. 
Sifat-Sifat Kepemimpinan

Sifat dan sikap yang dimiliki oleh seorang pemimpin merupakan penentu berhasil atau tidaknya seorang pemimpin dalam menjalankan roda pemerintahan. Sifat dan sikap yang dimiliki oleh pemimpin dapat di sempurnakan dengan mendalami, memedomani, dan mengamalkan ajaran-ajaran serta berbagai ilmu pengetahuan yang dipelajari. Menurut Arifin Abdul Rachman (1971: 102) dalam bukunya yang berjudul “Kerangka Pokok-pokok Mengenai Manajemen Umum" menyebutkan bahwa terdapat tiga golongan sifat-sifat para pemimpin, antara lain:

1. Sifat-sifat pokok, yaitu sifat-sifat dasar yang dimiliki oleh setiap pemimpin, antara lain adil, suka melindungi/mengayomi, penuh inisiatif, penuh daya tarik, dan penuh kepercayaan pada diri sendiri.

2. Sifat-sifat khusus karena pengaruh tempat, yaitu sifatsifat yang pada pokoknya sesuai dengan kepribadian bangsa, seperti bangsa Indonesia dengan Pancasila sebagai kepribadiannya, sebagai dasar negara, dan cita- cita bangsa.

3. Sifat-sifat khusus karena pengaruh dari berbagai macam atau golongan pemimpin, seperti pemimpin partai politik, pemimpin keagamaan, dan pemimpin serikat buruh

\section{Kepemimpinan Hindu dan Niti Sastra}

Kitab atau susastra Hindu yang banyak mengulas tentang konsepkonsep kepemimpinan termasuk etika dan moral di dalamnya disebut dengan kitab "Niti Sastra". Kata ini berasal dari Kata Sanskerta " niti " yang berarti bimbingan, dukungan, bijaksana, kebijakan, etika. Sedangkan " sastra “ berarti perintah, ajaran, nasihat, aturan, teori, dan tulisan ilmiah. Berdasarkan uraian diatas di atas maka kata Nitisastra berarti ajaran pemimpin. Dengan demikian ruang lingkup niti sastra tentu sangat luas mencakup pula etika, moralitas, sopan santun dan sebagainya. Dari pemahaman etimologis tersebut maka " niti sastra" dapat diartikan sebagai keseluruhan sastra yang memberikan ketentuan, bimbingan, arahan bagi umat manusia dalam berbagai aspek kehidupan agar menjadi lebih teratur, terarah, dan lebih baik.

Selama ini fokus atau pokok bahasan yang menjadi topik dari niti sastra adalah Kautilya Artha Sastra. Hal ini disebabkan oleh beberapa alasan sebagai berikut: Pertama, Kautilya adalah ahli politik dan kenegaraan 
tersohor; Kedua, kelengkapan dan kecermatan Kautilya dalam menyusun karyanya; Ketiga, bahasanya sangat mendetail; Keempat, perbandingan opini penyusun sebelumnya; Kelima, ketersediaan dokumen dan hanya dokumen Kautilya Artha Sastra ditemukan secara utuh. dalam beberapa konteks tertentu, ajaran Arthasastra masih cukup relevan, bahkan masih bisa dilakukan dalam kehidupan praktis. Untuk sampai mempraktekkannya kini, tentu saja tidak cukup membutuhkan good will tetapi political will. Konsep filsafat politik Kautilya yang masih bagus untuk dirawat, antara lain:

Pertama, pemimpin itu juga sekaligus pemikir. Konsep ini memiliki kesamaan dengan pemikiran Plato dalam The Republic sebagai The Philosopher King, yakni raja juga sekaligus pemikir yang bijak. Seorang raja sekaligus menjadi seorang pemimpin sehingga identitas tersebut menjadi satu kesatuan. Kedua, keteraturan negara akan baik kalau disokong oleh nilai-nilai bersama di mana moralitas individu menjadi panglima. Keteraturan negara menurut Kautilya akan tetap terjaga apabila seorang pemimpin memiliki ketegasan untuk mempertahankan kedaulatan negaranya diatas segalanya, terbebas dari intimidasi golongan atau kelompok lain yang ingin mengganti kedaulatan negaranya. Ketiga, pemimpin itu harus dipersiapkan secara matang. Oleh Kautilya disebut swamin yang berhasil dilakukannya pada diri Chandragupta. Kebesaran Kautilya justru terletak bukan saja karena gagasan politiknya begitu lengkap dan utuh dalam Arthasastra, tetapi pribadinya yang komplit baik sebagai politikus dan rohaniwan (pandit) adalah tokoh yang mampu mengawinkan dua dunia berbeda sekaligus, yakni dunia material dan dunia spiritual. Sebagai seorang politikus yang religius, Kautilya hadir sebagai sosok langka dan menjadi autokritik yang menampar generasi masa kini yang lebih banyak hidup dalam ruang abu-abu demi mempertahankan kenyamanan hidup tanpa karakter (Segara, 2013).

Untuk itulah seseorang dianjurkan untuk mempelajari niti sastra apabila ingin memahami kepemimpinan Hindu atau kepemimpinan yang universal Mengingat, pengetahuan dan pemahaman sejarah/konsep pemikiran Hindu (niti sastra) di bidang Politik, ketatanegaraan, ekonomi, dan hukum yang masih relevan sampai kini. Konsep-konsep tersebut adalah sumber penting yang memberi kontribusi perkembangan konsep-konsep selanjutnya di India, Asia bahkan, 
dunia. Kontribusi niti sastra dalam peradaban global antara lain:

1) Pemikiran dalam niti sastra dapat memberi masukan penting berupa konsep dan nilai positif dalam pengembangan, pembaharuan, penyusunan kembali konsep-konsep politik, ketatanegaraan, ekonomi, peraturan hukum era kini.

2) Usaha menggali, mengangkat nilai-nilai Hindu sebagai sumbangan Hindu dalam percaturan dunia keilmuan. Paradigma sosial bahwa politik itu kotor dapat hilang.

Negara sebagai wadah umat manusia untuk mewujudkan citacita hidupnya memiliki empat prinsip dasar. Antara lain sebagai berikiut :

1) Machstaat adalah prinsip Negara untuk menguasai segala potensi yang dimiliki oleh negarayang bersangkutan untuk diabdikan kembali pada tujuan masyarakat Negara itu.

2) Rechtaat adalah prinsip Negara yang bertujuan untuk mengatur kehidupan Negara yang bertujuan untuk mengatur kehidupan Negara agar berbagai keadaan dan kepentingan yang berbeda - beda dapat diatur dalam rangka mempercepat tercapainya tujuan Negara.
3) Polisistaat adalah suatu prinsip Negara yang memandang segala seluk beluk kehidupan Negara harus dijaga agar tidak terjadi penyimpangan - penyimpangan demi terwujudnya tujuan Negara tepat pada sasarannya.

4) Supervisorystaat adalah prinsip Negara yang memandang bahwa fungsi Negara ialah mendorong segala unsur - unsur Negara untuk lebih cepat mencapai tujuan.

Bagi umat yang mendapat kesempatan sebagai pemimpin Negara, tuntunan ajaran agama hindu bertujuan untuk membentuk kepemimpinan Negara yang baik,kuat, bersih, dan berwibawa. Masyarakat akan lebih mudah diatur oleh para pemimpin Negara apabila dalam masyarakat itu tiap - tiap anggotanya sadar akan hak dan kewajibannya. Kesejahteraan masyarakat Negara akan terwujud apabila setiap warga Negara mau berjuang untuk mensejahterakan dirinya, keluarga,dan lingkungannya. Diri pribadi umat manusia akan tentram apabila atmanya menguasai budhi,budhinya menguasai manah,manahnya menguasai perasaan atau manahnya dikuasai oleh rajas,rajasnya dikuasai oleh tamas, dan tamasnya dikuasai oleh sattwam. Pemimpin Negara harus memiliki 
konsep - konsep kepemimpinan yang utama untuk dapat menata Negaranya. Hal ini dapat berarti kewibawaan pemimpin Negara harus didasarkan pada kewibawaan yang murni dan bukan atas kewibawaan yang dilandisi oleh kekuasaan.

\section{Penerapan Konsep Kepemimpinan dalam Hindu}

Dalam konsep kepemimpinan Barat yang lebih banyak dijadikan dasar adalah sikap dan tingkah laku dari para pemimpin-pemimpin besar di dunia. Oleh kerena itu mereka banyak mengemukakan jenis-jenis kepemimpinan yang sesuai dengan tokoh personalnya, seperti : kepemimpinan Karismatik, kepemimpinan Paternalistik, kepemimpinan Maternalistik, kepemimpinan Militeristik, kepemimpinan Otokrasi, kepemimpinan Lassez Faire, kepemimpinan Populistik, kepemimpinan Eksekutif, kepemimpinan Demokratik, kepemimpinan Personal, kepemimpinan Sosial dan masih banyak lagi lainnya.

Lain halnya dengan konsep kepemimpinan dalam ajaran Hindu. Selain dasar tersebut, yang terutama dalam kepemimpinan Hindu adalah bersumber dari kitab suci Weda dan diajarkan oleh para orang-orang suci. Kepemimpinan Hindu juga banyak mengacu pada tatanan alam semesta yang merupakan ciptaan dari Tuhan Yang Maha Esa. Adapun konsepkonsep kepemimpinan Hindu yang banyak diajarkan dalam sastra dan susastranya antara lain: Sad Warnaning Rajaniti, Catur Kotamaning Nrpati, Tri Upaya Sandi, Pañca Upaya Sandi, Asta Brata, Nawa Natya, Pañca Dasa Paramiteng Prabhu, Sad Upaya Guna, dan Pañca Satya (Ngurah, 2006: 194). Salah satu contoh dari konsep-konsep kepemimpinan Hindu seperti

Sad Warnaning Rajaniti adalah enam sifat utama dan kemampuan yang harus dimiliki oleh seorang raja (Ngurah, 2006: 196). Konsep ini ditulis oleh Candra Prkash Bhambari dalam buku "Substance of Hindu Politiy." Bagian-bagian Sad Warnaning Rajaniti sebagai berikut adalah :

a. Abhigamika, artinya seorang raja atau pemimpin harus mampu menarik perhatian positif dari rakyatnya.

b. Prajña, artinya seorang raja atau pemimpin harus bijaksana.

c. Utsaha, artinya seorang raja atau pemimpin harus memiliki daya kreatif yang tinggi.

d. Atma Sampad, artinya seorang raja atau pemimpin harus bermoral yang luhur.

e. Sakya samanta, artinya seorang raja atau pemimpin 
harus mampu mengontrol bawahannya dan sekaligus memperbaiki hal-hal yang di anggap kurang baik.

f. Aksudra Parisatka, artinya seorang raja atau pemimpin harus mampu memimpin sidang para menterinya dan dapat menarik kesimpulan yang bijaksana sehingga diterima oleh semua pihak yang mempunyai pandangan yang berbeda-beda.

Contoh sifat-sifat kepemimpinan yang lain adalah Catur Kotamaning Nrpati. Catur Kotamaning Nrpati merupakan konsep kepemimpinan Hindu pada zaman Majapahit sebagaimana ditulis oleh M. Yamin dalam buku "Tata Negara Majapahit" (Ngurah, 2006: 196). Catur Kotamaning Nrpati adalah empat syarat utama yang harus dimiliki seorang pemimpin yang terdiri dari:

a. Jñana Wisesa Suddha, artinya raja atau pemimpin harus memiliki pengetahuan yang luhur dan suci. Dalam hal ini ia harus memahami kitab suci atau ajaran agama (agama agëming aji).

b. Kaprahitaning Praja, artinya raja atau pemimpin harus menunjukkan belas kasihnya kepada rakyatnya. Raja yang mencintai rakyatnya akan dicintai pula oleh rakyatnya.

c. Kawiryan, artinya seorang raja atau pemimpin harus berwatak pemberani dalam menegakkan kebenaran dan keadilan berdasarkan pengetahuan suci yang dimilikinya.

d. Wibawa, artinya seorang raja atau pemimpin harus berwibawa terhadap bawahan dan rakyatnya. Raja yang berwibawa akan disegani oleh rakyat dan bawahannya.

Pentingnya peran pemimpin pun termaktub dalam kitab Manawa Dharmasastra bab VII, 2 dan 3 ada disebutkan pentingnya ada negara dan pemerintah untuk melindungi rakyat. Manawa Dharmasastra itu berbunyi sebagai berikut :

Brahmapraptena samskaramk satriyena yata widhi, sarwasyasya yathanyayam kartawyam pariraksanam.

(Manawa Dharmasastra VII.2)

Terjemahannya :

Ksatriya yang telah menerima sakramen menurut Weda, berkewajiban melindungi seluruh dunia sebaik-baiknya.

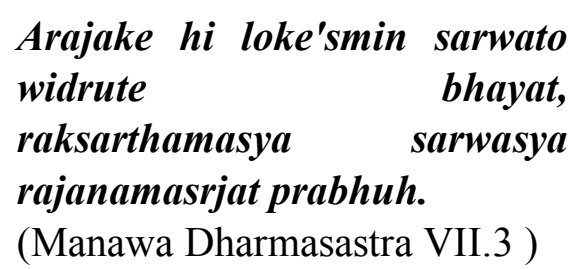


Terjemahannya :

Karena, kalau orang-orang ini tanpa raja akan terusir, tersebuar keseluruh penjuru oleh rasa takut. Tuhan telah menciptakan raja untuk melindungi seluruh ciptaannya.

Dalam agama Hindu, banyak ditemukan istilah yang menunjuk pada pengertian pemimpin. Bila bakat kepemimpinannya yang menonjol dan mampu memimpin sebuah organisasi dengan baik disebut Ksatriya, karena kata ksatriya artinya yang memberi perlindungan. Demikian pula yang memiliki kecerdasan yang tinggi, senang terjun di bidang spiritual, ia adalah seorang Brahmana. Demikian pula profesi-profesi masyarakat seperti pedagang, bussinessman, petani, nelayan dan sebagainya.

Dalam sejarah Hindu banyak contoh pemimpin yang perlu dijadikan suri teladan. Di setiap jaman dalam sejarah Hindu selalu muncul tokoh yang menjadi pemimpin. Sebut saja Erlangga, Sanjaya, Ratu Sima, Sri Aji Jayabhaya, Jayakatwang, Kertanegara, Hayam Wuruk, Gajah Mada, dan masih banyak lagi lainnya. Di era sekarang banyak tokoh Hindu yang juga dapat dijadikan sebagai panutan/pimpinan seperti : Mahatma Gandhi, Svami Vivekananda, Ramakrsna, Sri Satya Sai dan sebagainya.
Selain itu contoh kepemimpinan Hindu yang ideal dapat ditemukan dalam cerita Itihasa dan Purana. Banyak tokoh dalam cerita tersebut yang diidealkan menjadi pemimpin Hindu. Misalnya: Dasaratha, Sri Rama, Wibhisana, Arjuna Sasrabahu, Pandudewanata, Yudisthira dan lainlain.

\section{Contoh Kepemimpinan Dalam Cerita} Yudhistira

Berdasarkan cerita kepemimpinan Yudhistira, pada suatu hari, Pandu mengutarakan niatnya ingin memiliki anak. Kunti yang menguasai mantra Adityahredaya, atas anugerah rsi Durvasa segera mewujudkan keinginan suaminya tesebut. Mantra tersebut adalah ilmu untuk pemanggil dewa untuk mendapatkan putera. Dengan menggunakan mantra itu, Kunti berhasil mendatangkan Dewa Dharma. Kunti pun mendapatkan anugerah putera darinya tanpa me- lalui hubungan badan. Putra tersebut diberi nama Yudhistira.

Dengan demikian, Yudhistira menjadi putera sulung Pandu, sebagai hasil pemberian Dharma, yaitu dewa keadilan dan kebijaksanaan. Sifat Dharma itulah yang kemudian diwarisi oleh Yudhistira sepanjang hidupnya. Yudhistira alias Dharmawangsa, merupakan seorang raja yang 
memerintah kerajaan Kuru, dengan pusat pemerintahan di Hastinapura. Ia adalah yang tertua di antara lima Pandawa, atau para putra Pandu. Nama Yudhistira dalam bahasa Sanskerta bermakna "teguh atau kokoh dalam peperangan." Ia juga dikenal dengan sebutan Dharmaraja, yang bermakna "Raja Dharma," karena ia selalu berusaha menegakkan dharma sepanjang hidupnya. Delapan nama Yudhistira atau julukan yang dikenal dalam cerita Mahabharata adalah sebagai berikut:

1. Ajatasatru, yaitu tidak memiliki musuh.

2. Bharata, ialah keturunan Maharaja Bharata.

3. Dharmawangsa atau Dharmaputra, "keturunan Dewa Dharma."

4. Kurumukhya, "pemuka bangsa Kuru."

5. Kurunandana, "kesayangan Dinasti Kuru."

6. Kurupati, "raja Dinasti Kuru."

7. Pandawa, "putra Pandu".

8. Partha, "putra Prita atau Kunti". Selain delapan nama julukan tersebut, ada empat nama julukan yang dikenal dalam cerita pewayangan antara lain:

1. Puntadewa, "derajat keluhurannya setara para dewa,"
2. Yudhistira, "pandai memerangi nafsu pribadi,"

3. Gunatalikrama, "pandai bertutur bahasa,"

4. Samiaji, "menghormati orang lain bagai diri sendiri."

Selanjutnya, terjadi pernikahan antara Pandawa dengan Drupadi. Setelah itu para Pandawa kembali ke Hastinapura dan memperoleh sambutan luar biasa, kecuali dari pihak Duryodana. Persaingan antara Pandawa dan Korawa atas tahta Hastinapura kembali terjadi. Para sesepuh akhirnya sepakat untuk memberi Pandawa sebagian dari wilayah kerajaan tersebut. Korawa yang licik mendapatkan Istana Hastinapura, sedangkan Pandawa mendapatkan hutan Kandawaprastha sebagai tempat untuk membangun istana baru.

Meskipun daerah tersebut sangat gersang dan angker, namun para Pandawa mau menerima wilayah tersebut. Selain wilayahnya yang luas hampir setengah wilayah Kerajaan Kuru, Kandawaprastha juga merupakan ibu kota Kerajaan Kuru yang dulu, sebelum Hastinapura. Para Pandawa dibantu sepupu mereka, yaitu Kresna dan Baladewa berhasil membuka Kandawaprastha menjadi pemukiman baru.

Para Pandawa kemudian memperoleh bantuan dari Wiswakarma, 
yaitu ahli bangunan dari kahyangan, dan juga Anggaraparna dari Bangsa Gandharwa. Dengan bantuan tersebut, sehingga terciptalah sebuah istana megah dan indah bernama Indraprastha, yang bermakna "Kota Dewa Indra". Dalam versi pewayangan Jawa, nama Indraprastha lebih terkenal dengan sebutan Kerajaan Amarta. Menurut versi ini, hutan yang dibuka para Pandawa bukan bernama Kandawaprastha, melainkan bernama Wanamarta. Versi Jawa mengisahkan, setelah sayembara Drupadi, para Pandawa tidak kembali ke Hastinapura melainkan menuju kerajaan Wirata, tempat kerabat mereka yang bernama Prabu Matsyapati berkuasa. Matsyapati yang bersimpati pada pengalaman Pandawa menyarankan agar mereka membuka kawasan hutan tak bertuan bernama Wanamarta menjadi sebuah kerajaan baru. Hutan Wanamarta dihuni oleh berbagai makhluk halus.

Pekerjaan Pandawa dalam membuka hutan tersebut mengalami banyak rintangan. Akhirnya setelah melalui suatu percakapan, para makhluk halus merelakan Wanamarta kepada para Pandawa. Prabu Yudhistira kemudian memindahkan istana Amarta dari alam jin ke alam nyata untuk dihuni para Pandawa. Setelah itu, ia dan keempat adiknya menghilang. Salah satu versi menyebut kelimanya masing- masing menyatu ke dalam diri lima Pandawa. Puntadewa kemudian menjadi Raja Amarta setelah didesak dan dipaksa oleh keempat adiknya. Untuk mengenang dan menghormati raja jin yang telah memberinya istana, Puntadewa pun memakai gelar Prabu Yudhistira.

Setelah menjadi Raja Amarta, Puntadewa atau Yudhistira berusaha keras untuk memakmurkan negaranya. Konon terdengar berita bahwa barang siapa yang dapat menikahi puteri Kerajaan Slagahima yang bernama Dewi Kuntulwinanten, maka negeri tempat ia tinggal akan menjadi makmur dan sejahtera. Puntadewa sendiri telah memutuskan untuk memiliki seorang istri saja. Namun karena Dropadi mengizinkannya menikah lagi demi kemakmuran negara, maka ia pun berangkat menuju Kerajaan Slagahima. Di istana Slagahima telah berkumpul sekian banyak raja dan pangeran yang datang melamar Kuntulwinanten. Namun sang puteri hanya sudi menikah dengan seseorang yang berhati suci, dan ia menemukan kriteria itu dalam diri Puntadewa. Kemudian Kuntulwinanten tiba-tiba musnah dan menyatu ke dalam diri Puntadewa. Sebenarnya Kuntulwinanten bukan manusia asli, melainkan wujud penjelmaan anugerah dewata untuk seorang raja adil yang 
hanya memikirkan kesejahteraan negaranya (Subramanyam, 2007).

Dari cerita di atas, kita dapat melihat bahwa Yudhistira adalah seorang pemimpin yang mengutamakan kepentingan umum. Yudhistira merupakan salah satu dari sedikit Raja yang mendapatkan gelar Maharaja, yaitu rajanya para raja. Gelar ini diperoleh setelah saudaranya, Bima, berhasil menaklukan Maharaja Jasaranda dalam duel sengit. Yudhistira dapat dikatakan jarang ikut turun dalam medan laga dibanding saudarasaudaranya, namun kemampuannya dalam memimpin pemerintahan tidak diragukan lagi. Indraprasta kerajaan yang dipimpinnya (setelah Destarata membagi Hastinapura menjadi dua bagian untuk Pandawa dan Kurawa), menjadi negeri yang melimpah kekayaannya. Yudhistira memiliki kemampuan, pemikiran, dan perencanaan yang sangat baik dalam membangun pemerintahan maupun strategi perang. Yudhistira juga seorang yang berpikir singkat namun pemikirannya tersebut memiliki efek jangka panjang. Hal ini tak lepas dari segala pengetahuan yang sangat luas yang dimilikki olehnya.

Kepemimpinan yang berlandaskan ajaran Agama Hindu tentunya dapat mengaktualisasikan ajaran Agama Hindu. Untuk itu fungsi- fungsi agama bagi kehidupan manusia harus disadari dan dipahami oleh seorang pemimpin, sebab membahas kepemimpinan Hindu tidak dapat melepaskan diri untuk tidak mengkaji ajaran Agama Hindu. Dalam hubungannya dengan kehidupan manusia, agama dan juga pemimpin atau kepemimpinan mempunyai fungsifungsi sebagai berikut :

1. Sebagai faktor motivatif, mendorong, mendasari, melandasi cita-cita dan amal perbuatan manusia dalam seluruh aspek kehidupannya.

2. Sebagai faktor kreatif, produktif dan innovatif, mendorong dan mengharuskan untuk tidak hanya melakukan kerja produktif saja, tetapi juga kreatif dan innovatif.

3. Sebagai faktor integratif, memadukan segenap aktivitas manusia baik sebagai individu maupun sebagai anggota masyarakat dalam berbagai bidang kehidupan. Keyakinan dan penghayatan terhadap ajaran agama akan menghindarkan manusia dari situasi dan kepribadiannya yang pecah. Dengan keutuhan kepribadiannya itu manusia akan mampu menghadapi berbagai macam tantangan dan resiko kehidupan. 
4. Sebagai faktor sublimatif atau transformatif, mampu mengubah sikap dan prilaku, perkataan maupun perbuatan sesuai sesuai dengan ajaran agama.

5. Sebagai faktor inspiratif, memberikan inspirasi bagi pengembangan seni dan budaya yang dijiwai oleh Agama Hindu.

\section{SIMPULAN}

Berdasarkan uraian diatas maka dapat disimpulkan hal-hal sebagai berikut :

1. Penerapan konsep kepemimpinan dalam Hindu bersumber dari kitab suci Weda dan diajarkan oleh para orang-orang suci. Adapun konsepkonsep kepemimpinan Hindu yang banyak diajarkan dalam sastra dan susastranya antara lain: Sad Warnaning Rajaniti, Catur Kotamaning Nrpati, Tri Upaya Sandi, Pañca Upaya Sandi, Asta Brata, Nawa Natya, Pañca Dasa Paramiteng Prabhu, Sad Upaya Guna, dan Pañca Satya

2. Sifat-sifat kepemimpinan yang ideal terdiri dari tiga golongan, yaitu sifat-sifat pokok (sifat-sifat dasar yang dimiliki oleh setiap pemimpin, antara lain adil, suka melindungi/mengayomi, penuh inisiatif, penuh daya tarik, dan penuh kepercayaan pada diri sendiri), sifat-sifat khusus karena pengaruh tempat (yaitu sifat-sifat yang pada pokoknya sesuai dengan kepribadian bangsa, seperti bangsa Indonesia dengan Pancasila sebagai kepribadiannya, sebagai dasar negara, dan cita- cita bangsa), dan sifat-sifat khusus karena pengaruh dari berbagai macam atau golongan pemimpin (seperti pemimpin partai politik, pemimpin keagamaan, dan pemimpin serikat buruh).

3. Berdasarkan tinjauan terminologis, etimolis dan semantik serta berdasar kutipan-kutipan terjemahan mantra Veda dan terjemahan sloka-sloka kitab Arthasastra maka dapat dirumuskan fungsi-fungsi kepemimpinan dalam Hindu atas dua jenis fungsi, yaitu:

a. Melindungi masyarakat, memberikan rasa aman, bertanggung jawab serta memberikan bimbingan kepada warganya untuk turut mewujudkan rasa aman dan tentram dikalangan mereka (fungsi security).

Mewujudkan kemakmuran bersama-sama anggota masyarakat untuk mewujudkan kesejahtraan, kemakmuran dan melepaskan pederitaan masyarakat lahir dan batin (fungsi prosperity). 
DAFTAR PUSTAKA

Ngurah, Drs. I Gusti Made. 1998. Buku

Pendidikan Agama Hindu Untuk

Perguruan Tinggi. Surabaya:

Paramita

Gorda, I Gusti Ngurah. 2006. Manajemen Sumber Daya Manusia. Cetakan Ketiga. Denpasar : Asta Brata Bali

Maswinara, I Wayan. 2003. Manawa Dharmasastra. Surabaya: Paramita

Nurwardani, Paristiyanti dkk. 2016. Buku Ajar Mata Kuliah Wajib Umum Pendidikan Agama Hindu. Jakarta: Direktorat Jenderal Pembelajaran dan Kemahasiswaan Kementerian Riset Teknologi dan Pendidikan Tinggi.

Pendit, Nyoman S.2003. Mahabharata. Jakarta : Gramedia Pustaka Utama

Rahman, Arifin Abdul.1971. Pengembangan \& Filososfi Kepemimpinan Kerja. Bharata: Jakarta.

Suhardana. 2008. Niti Sastra : Ilmu Kepemimpinan atau
Management Berdasarkan

Agama Hindu. Surabaya:

Paramita Surabaya

Suhardi,Untung dkk. 2015. Pendidikan Agama Hindu dan Budi Pekerti. Jakarta: Kementerian Pendidikan dan Kebudayaan RI.

https://www.mediahindu.net/2011/09/24 /korupsi-kegagalan-parapemimpin-agama/ (diakses pada tanggal 9 Mei 2018)

http://www.benuailmu.com/2013/10/ast a-bratha-adalah.html (diakses pada tanggal 9 Mei 2018)

https://www.kompasiana.com/peradah/a jaran-asta-brata-sebagaipedoman-kepemimpinanhindu_552dfe146ea83495138b4 $5 \mathrm{~b} 0 \quad$ (diakses pada tanggal 10 Mei 2018)

https://paduarsana.com/2012/07/11/kep emimpinan-dalamhindu/(diakses pada tanggal 10 Mei 2018). 